\title{
DOSES E ÉPOCAS DE APLICAÇÃO DE NITROGÊNIO EM COBERTURA NA CULTURA DO PAINÇO (Panicum miliaceum L.)
}

\author{
Doses and time of nitrogen top-dressed application on proso \\ millet crop (Panicum miliaceum L.)
}

\author{
Rogério Peres Soratto ${ }^{1}$, Susiane de Moura Cardoso ${ }^{2}$, Ângela Honório da Silva ${ }^{2}$, \\ Tiago Aparecido Mingotti da Costa ${ }^{2}$, Magno Pereira ${ }^{2}$, Laércio Alves de Carvalho ${ }^{3}$
}

\begin{abstract}
RESUMO
A cultura do painço é uma opção interessante tanto para a formação de palha para cobertura do solo como para a produção de grãos, pelo seu rápido crescimento, tolerância à seca e ciclo curto. No entanto, são escassas as informações sobre o manejo da adubação nitrogenada para essa cultura. Objetivou-se, neste estudo, avaliar o efeito de doses e épocas de aplicação de nitrogênio em cobertura nas características agronômicas e produtividade de grãos do painço. O delineamento experimental foi o de blocos ao acaso, em esquema fatorial $4 \times 2$, constituído pela combinação de quatro doses $\left(0,30,60\right.$ e $\left.120 \mathrm{~kg} \mathrm{ha}^{-1} \mathrm{de} \mathrm{N}\right)$ e duas épocas de aplicação (14 e 28 dias após a emergência - DAE) do fertilizante nitrogenado (uréia) em cobertura, com quatro repetições. A adubação nitrogenada em cobertura promoveu aumento na altura da planta, comprimento da panícula e produtividade de grãos da cultura do painço, independentemente da época de aplicação. O número de grãos por panícula foi incrementado pela adubação nitrogenada apenas com a aplicação que foi realizada aos 14 DAE. A aplicação de $\mathrm{N}$ em cobertura, aos 14 dias após a emergência, proporcionou acréscimos nas características agronômicas, até a dose de $120 \mathrm{~kg} \mathrm{ha}^{-1}$ (maior dose), acarretando aumento da produtividade de grãos do painço.
\end{abstract}

Termos para indexação: Adubação nitrogenada, nutrição mineral, componentes da produção, produtividade de grãos.

\section{ABSTRACT}

Proso millet crop is an interesting option for soil cover crop and grain production, due to fast growth, drought tolerance and short cycle. However, data about nitrogen fertilization management in this crop are scarce. The objective of this work was to evaluate the effect of doses and times of nitrogen top-dressed application on agronomic characteristics and grain yield of proso millet. A randomized complete block design in a $4 \times 2$ factorial scheme, constituted by the combination of four doses $(0,30,60$, and $120 \mathrm{~kg}$ ha ${ }^{1}$ of $\mathrm{N}$ ) and two application times (14 and 28 days after emergency) of nitrogen fertilizer (urea) in topdressing with four replications was used. Nitrogen topdressed fertilization promoted increase in plant height, length of panicle and grain yield of proso millet crop, independently of application time. Number of grains per panicle was increased by nitrogen fertilization only with application accomplished 14 days after emergence. The topdressing nitrogen application up to the highest dose $\left(120 \mathrm{~kg} \mathrm{ha}^{-1}\right), 14$ days after plant emergence, led to an increase in agronomic characteristics and grain yield of proso millet.

Index terms: Nitrogen fertilization, mineral nutrition, yield components, grain yield.

(Recebido em 13 de julho de 2006 e aprovado em 15 de março de 2007)

\section{INTRODUÇÃO}

A diversificação do sistema produtivo depende da utilização de espécies com rápido crescimento, tolerância ao déficit hídrico, produção de biomassa e utilização humana e animal (SPEHAR \& LARA CABEZAS, 2001). Nesse sentido, o painço (Panicum miliaceum L.), uma gramínea de ciclo anual, originária da África, vem sendo cultivada em algumas regiões do estado de São Paulo e Mato Grosso do Sul com a finalidade de exploração econômica dos grãos, utilização na alimentação animal principalmente de pássaros em cativeiro, substituindo o alpiste (FURUHASHI, 1995; ZANCANELLA et al., 2003). É também empregado na indústria cervejeira, misturado em pequena proporção com a cevada (LIMA et al., 2000).

Recentemente, o painço está sendo também utilizado como adubação verde e para obtenção de palhada destinada à cobertura do solo para o sistema de plantio direto (LIMA, 2004; ZANCANELLA et al., 2006), tendo como vantagens o baixo custo e a rapidez de formação abundante de palha. Além disso, pode ser semeado durante

\footnotetext{
Engenheiro Agrônomo, Doutor, Professor Assistente - Departamento de Produção Vegetal - Faculdade de Ciências Agronômicas/FCA - Universidade Estadual Paulista/UNESP - Rua José Barbosa de Barros, 1780 - Cx. P. 237 - 18610-307 - Botucatu, SP - soratto@fca.unesp.br

${ }^{2}$ Graduandos em Agronomia - Unidade Universitária de Cassilândia/UUC - Universidade Estadual de Mato Grosso do Sul/UEMS - Rodovia MS 306, Km 06 -79540-000 - Cassilândia, MS - susianemoura@yahoo.com.br; angelhonorio@yahoo.com.br; tiagomingotti@hotmail.com; magnouems@bol.com.br ${ }^{3}$ Engenheiro Agrônomo, Doutor, Professor Adjunto - Unidade Universitária de Cassilândia/UUC - Universidade Estadual de Mato Grosso do Sul/UEMS Rodovia MS 306, Km 06 - 79540-000 - Cassilândia, MS - Icarvalh@uems.br
} 
praticamente todo o ano, desde que haja alguma disponibilidade de água e não existam riscos de geadas (ZANCANELLA et al., 2006). Em função do ciclo curto (70 dias em média), pode também ser uma espécie interessante para o cultivo de primavera, pois além da produção de palhada, haveria tempo suficiente para colheita dos grãos, não atrasando a época ideal de semeadura da cultura de verão, ou como uma alternativa de rotação, principalmente na safrinha (LIMA, 2004; ZANCANELLA et al., 2003).

O suprimento adequado de nutrientes é fundamental para a obtenção de altas produtividades (CLARK, 1990), especialmente com relação ao $\mathrm{N}$, que geralmente é o elemento requerido em maior quantidade pelas plantas (MALAVOLTA, 1979; MAMAN et al., 1999). O nitrogênio influencia positivamente os componentes da produção e, consequientemente, a produtividade de grãos das culturas, em razão das múltiplas funções desse nutriente na planta. Em cereais, a literatura relata respostas ao $\mathrm{N}$ em cobertura para massa da panícula, comprimento da panícula e massa de mil grãos em sorgo (SUBBA REDDY et al., 1991); número de panículas e comprimento das panículas de milheto (MAMAN et al., 1999; MESQUITA et al., 1998), número de panículas, número de grãos por panículas de arroz de terras altas (GUIMARÃES \& STONE, 2003) e número de panículas, comprimento da panícula, massa da panícula de milheto (JORNADA et al., 2005), em todos os casos com acréscimo na produtividade de grãos. Em aveia-preta ocorre maior produtividade de grãos com a aplicação do $\mathrm{N}$, no perfilhamento (NAKAGAWA et al., 1995).

Em condições de casa-de-vegetação, foi observado aumento na altura da planta, número de colmos por planta e produtividade de grãos de dois cultivares de painço em função da aplicação de N em cobertura (SORATTO et al., 2004). Contudo, há carência de resultados experimentais com relação à doses e épocas de aplicação de $\mathrm{N}$ em cobertura, em condições de campo.

Objetivou-se, neste trabalho avaliar o efeito de doses e épocas de aplicação de nitrogênio em cobertura nas características agronômicas e a produtividade de grãos do painço cv. AL Tibagi, em condições de campo.

\section{MATERIAL E MÉTODOS}

O trabalho foi realizado em área experimental pertencente à Universidade Estadual de Mato Grosso do Sul - UEMS, Unidade Universitária de Cassilândia, município de Cassilândia, MS (1905' 25" S, 51 $41^{\circ}$ ' 52" W, com altitude de $508 \mathrm{~m}$ ). O solo do local é um Neossolo Quartzarênico (EMBRAPA, 1999), cujas características granulométricas são: 877, 20 e $103 \mathrm{~g} \mathrm{~kg}^{-1}$ de areia, silte e argila, respectivamente. Os dados de precipitação obtidos durante a condução do experimento apresentam-se pela Figura 1.

Antes da instalação do experimento foi realizada amostragem de solo para a determinação das características químicas, na camada de 0-0,20 m, de acordo com método proposto por Raij et al. (2001), cujos resultados foram: 17,6 $\mathrm{g} \mathrm{dm}^{-3}$ de matéria orgânica, $\mathrm{pH}\left(\mathrm{CaCl}_{2}\right) 4,8 ; 3,8 \mathrm{mg} \mathrm{dm}^{-3} \mathrm{de}$ $\mathrm{P} ; 1,2 ; 12,6 ; 5,2$ e $21,9 \mathrm{mmol}_{\mathrm{c}} \mathrm{dm}^{-3}$ respectivamente de $\mathrm{K}$, $\mathrm{Ca}, \mathrm{Mg}$ e $\mathrm{H}+\mathrm{Al}$, e $46 \%$ de saturação por bases.

$\mathrm{O}$ experimento foi instalado em área anteriormente cultivada com pastagem. Em outubro de 2005, foi realizada na área calagem aplicando-se $1.400 \mathrm{~kg} \mathrm{ha}^{-1}$ de calcário dolomítico (PRNT de 72\%). Após a distribuição, o calcário foi incorporado com uma gradagem pesada $(0,17-0,20 \mathrm{~m}$ de profundidade) e uma gradagem leve. Às vésperas da semeadura, o solo foi preparado com duas gradagens com grade leve à profundidade de 0,10-0,12 m.

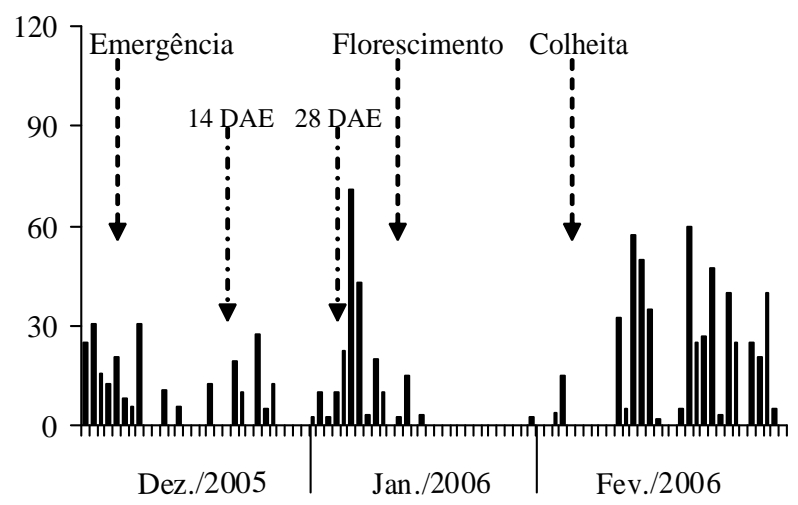

Figura 1 - Valores diários de precipitação pluvial (mm), coletados na área experimental, durante o período de dezembro de 2005 a fevereiro de 2006, e datas de emergência, florescimento e colheita em que a cultura do painço emergiu e atingiu o florescimento pleno. Cassilândia, MS.

$\mathrm{O}$ delineamento experimental utilizado foi o de blocos ao acaso, no esquema fatorial $4 \times 2$, com quatro repetições. Os tratamentos foram constituídos pela combinação de quatro doses de $\mathrm{N}\left(0,30,60\right.$ e $\left.120 \mathrm{~kg} \mathrm{ha}^{-1}\right)$ em cobertura, tendo como fonte a uréia, e duas épocas de aplicação: 14 dias após a emergência (DAE), ou seja, no estádio de perfilhamento, e 28 DAE, no estádio de emborrachamento. Cada parcela foi constituída por cinco linhas de 4,0 m de comprimento. A área útil foi constituída pelas três linhas centrais, desprezando-se $0,50 \mathrm{~m}$ nas extremidades de cada linha. 
A adubação de semeadura constou da aplicação, em todos os tratamentos, de $15 \mathrm{~kg} \mathrm{ha}^{-1}$ de $\mathrm{N}$ na forma de uréia, $60 \mathrm{~kg} \mathrm{ha}^{-1}$ de $\mathrm{P}_{2} \mathrm{O}_{5}$ na forma de superfosfato simples, $40 \mathrm{~kg} \mathrm{ha}^{-1}$ de $\mathrm{K}_{2} \mathrm{O}$ na forma de cloreto de potássio e $20 \mathrm{~kg}$ ha $^{-1}$ de F.T.E. BR-12 (9,0\% de Zn, 1,8\% de B, 0,8\% de Cu, 3,0\% de Fe, 2,0\% de Mn e 0,1\% de Mo). A distribuição da adubação básica foi realizada com uma semeadoraadubadeira tratorizada, regulada no espaçamento de 0,40 $\mathrm{m}$ e a profundidade de $0,08 \mathrm{~m}$. A semeadura foi realizada manualmente, em sulcos de $0,02 \mathrm{~m}$ de profundidade, abertos exatamente sobre as linhas onde havia sido distribuída a adubação, na data de 30/11/2005, utilizando o cultivar AL Tibagi, com densidade de 70-80 sementes viáveis por metro (viabilidade definida em teste de germinação preliminar). A emergência das plantas ocorreu dia 06/12/2005.

A cultivar AL Tibagi apresenta porte de 1,00-1,20 m de altura, ciclo de 65-80 dias, panículas fechadas e grãos achatados de coloração creme.

Nas adubações de cobertura, o adubo foi distribuído sobre a superfície do solo ao lado e aproximadamente $0,10 \mathrm{~m}$ das fileiras de plantas. $\mathrm{O}$ controle das plantas daninhas foi realizado mediante capina manual realizada aos 12 DAE. Durante o desenvolvimento da cultura não foi realizado nenhum outro trato cultural. A colheita foi realizada quando mais de $2 / 3$ das espiguetas apresentavam coloração típica de madura, ou seja, amareloclara ou creme.

Foram realizadas as seguintes avaliações: a) altura da planta: foi medida a distância média compreendida entre o nível do solo e a extremidade superior da panícula mais alta às véspera da colheita, em 10 plantas ao acaso, na área útil de cada parcela; b) comprimento da panícula: foi medida a distância média entre a inserção da primeira ramificação da ráquis e a extremidade superior da panícula, em 10 panículas coletadas ao acaso, por ocasião da colheita, na área útil de cada parcela; c) número de panículas por $\mathrm{m}^{2}$ : foi contado o número de panículas contidas em $2 \mathrm{~m}$ de fileira da área útil de cada parcela e posteriormente calculado o número por $\mathrm{m}^{2}$; d) número de grãos por panícula: foi contado o número de espiguetas contidas nas 10 panículas coletadas para determinação do comprimento da panícula e posteriormente calculado o número médio por panícula; e) massa de 1000 grãos: foi determinada mediante coleta ao acaso e pesagem de duas amostras de 1.000 grãos de cada parcela (valores foram corrigidos para $0,13 \mathrm{~kg} \mathrm{~kg}^{-1}$ ); $\mathrm{f}$ ) produtividade de grãos: foi realizada colheita manual em duas fileiras da área útil, de cada parcela; a seguir, foi realizada trilha manual, secagem à sombra e limpeza do material, separando-se a palha e as espiguetas chochas com auxílio de uma peneira, mediante abanação manual e, posteriormente foi determinada a massa de grãos colhidos para o calculo da produtividade de grãos. A umidade dos grãos foi corrigida para $0,13 \mathrm{~kg} \mathrm{~kg}^{-1}$.

Os resultados foram submetidos à análise de variância. As médias referentes à época de aplicação de $\mathrm{N}$ foram comparadas pelo teste t $(P=0,05)$, enquanto os efeitos das doses de nitrogênio foram avaliados pela análise de regressão, adotando-se como critério para escolha do modelo a magnitude dos coeficientes de regressão significativos ao nível de 5\%. Foram realizadas análises de correlação simples entre as características agronômicas da cultura do painço, visando determinar o grau de associação entre elas.

\section{RESULTADOS E DISCUSSÃO}

O florescimento pleno da cultura ocorreu 37 DAE e o ciclo teve a duração de 61 dias em todos os tratamentos (Figura 1). Durante o ciclo da cultura foram registrados na área experimental $368 \mathrm{~mm}$ de chuva (valor considerado normal para a região), ocorrendo precipitações logo após a realização das adubações nitrogenadas de cobertura, o que provavelmente reduziu as perdas por volatilização.

A aplicação de $\mathrm{N}$ em cobertura aumentou a altura da planta, independentemente da época de aplicação (Figura 2). No entanto, verificou-se resposta linear quando o nitrogênio foi aplicado aos 14 DAE (perfilhamento) e quadrática, quando a adubação foi realizada em época aos $28 \mathrm{DAE}$ (emborrachamento). Os resultados são semelhantes aos obtidos por Soratto et al. (2004), que também verificaram aumento na altura da planta de painço com a aplicação de $\mathrm{N}$ em cobertura aos 25 DAE. A aplicação da maior dose (120 kg ha-1) aos 14 DAE proporcionou maior altura da planta do que quando aplicada aos 28 DAE, o que está ligado ao fato de que o $\mathrm{N}$ influencia diretamente a divisão e a expansão celular e o processo fotossintético (MALAVOLTA et al., 1997), podendo causar aumento do crescimento vegetal, principalmente quando disponibilizado em época em que esse processo está ocorrendo com maior intensidade. $\mathrm{O}$ fornecimento inadequado de $\mathrm{N}$, na fase de ativo crescimento vegetativo, reduz o acúmulo de carboidratos resultantes da menor fotossíntese o que levou à obtenção de plantas com menor altura de plantas de Setaria italica (L.) Beauv. (BASAVARAJAPPA et al., 2003). É importante ressaltar que não houve acamamento de plantas mesmo com a aplicação das maiores doses de N. 

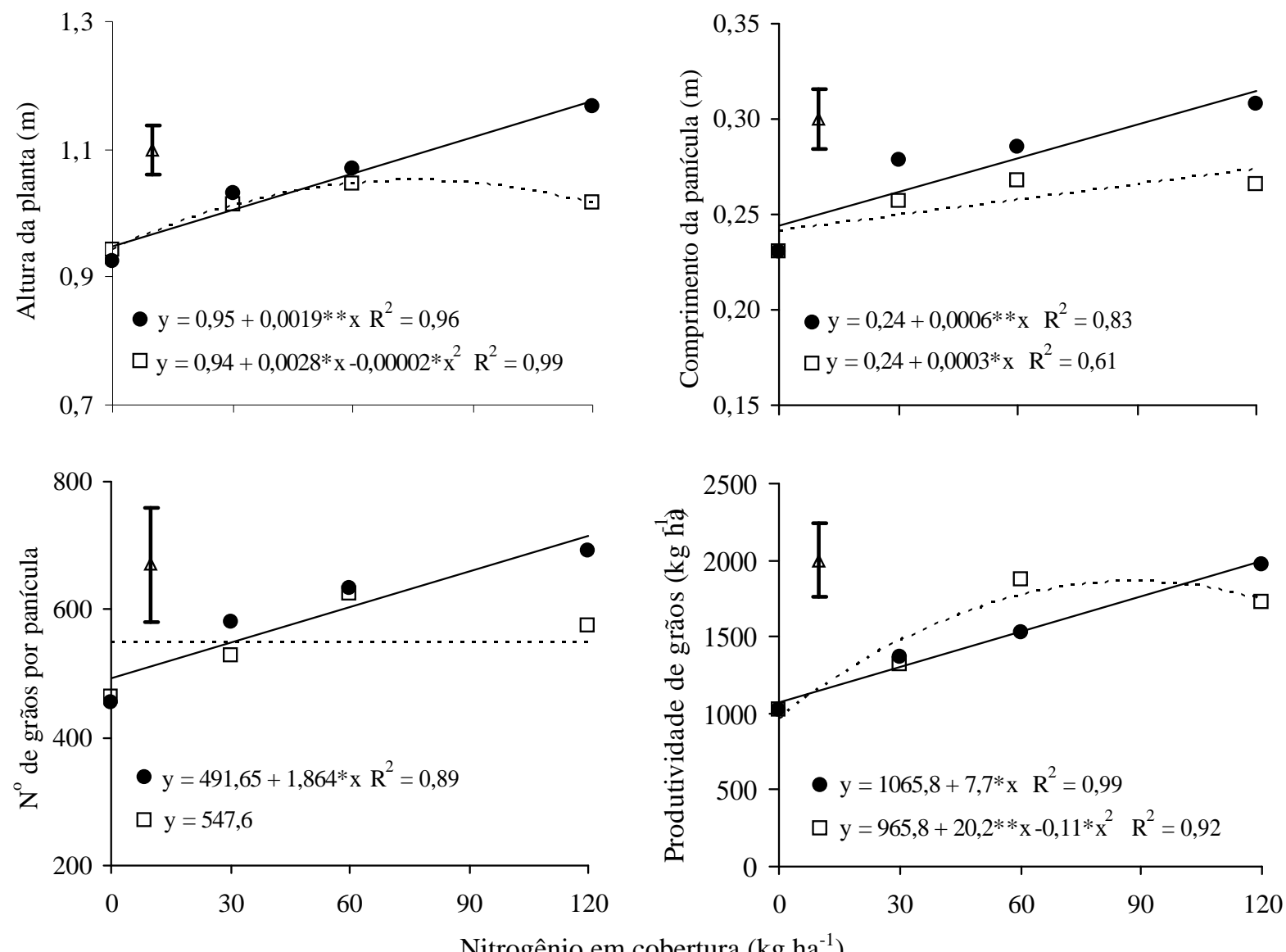

Nitrogênio em cobertura $\left(\mathrm{kg} \mathrm{ha}^{-1}\right)$

Figura 2 - Altura da planta, comprimento média da panícula, número médio de grãos por panícula e produtividade de grãos da cultura do painço em função de doses de N aplicado em cobertura, aos 14 DAE ( $\mathrm{e} 28$ DAE ( $\square$ ). * e ** são, respectivamente, significativos a $5 \%$ e $1 \%$ de probabilidade pelo teste t. Barras verticais indicam o valor de DMS $(P=0,05)$.

O comprimento da panícula foi influenciado de forma linear pela aplicação de $\mathrm{N}$ em cobertura (Figura 2). Contudo, verifica-se que o incremento da dose de $\mathrm{N}$, aplicada aos 14 DAE, proporcionou aumento mais acentuado no comprimento da panícula, em relação aos tratamentos onde o $\mathrm{N}$ foi aplicado aos $28 \mathrm{DAE}$, provavelmente por proporcionar às plantas maior disponibilidade do nutriente, na época de diferenciação da panícula. A resposta linear indica que, provavelmente com doses maiores de $\mathrm{N}$ poderão ser obtidas panículas maiores, até certos limites. Ocorre aumento no comprimento da panícula de milheto (Pennisetum americanum (L.) Leeke) e painço português (Setaria italica (L.) Beauv.), em função da aplicação de N (BASAVARAJAPPA et al., 2003; JORNADA et al., 2005; MESQUITA et al., 1998). Para
Carambula \& Elizondo (1968), um dos maiores benefícios do $\mathrm{N}$, na produção de sementes de gramíneas forrageiras, é o aumento do tamanho da inflorescência e, consequentemente do número de espiguetas, já que existe correlação positiva entre essas características (Tabela 1), conforme verificou-se também no presente experimento.

$\mathrm{O}$ número de panícula por $\mathrm{m}^{2}$ não foi influenciado pelas doses de nitrogênio nem pela época de aplicação do fertilizante, com valores médios de 144 e 145 por $\mathrm{m}^{2}$ para aplicação aos 14 e 28 DAE, respectivamente. O acompanhamento do experimento no campo permitiu constatar que, nas condições experimentais, as plantas de painço apresentaram pouco ou nenhum perfilhamento, mesmo nas maiores doses de $\mathrm{N}$, semelhante ao verificado por Soratto et al. (2004). 
Tabela 1 - Coeficientes de correlação simples (r) entre características agronômicas da cultura do painço.

\begin{tabular}{|c|c|c|c|c|c|}
\hline Variável & $\begin{array}{l}\text { Comprimento da } \\
\text { panícula }\end{array}$ & $\begin{array}{c}\mathrm{N}^{\mathrm{o}} \mathrm{de} \\
\text { panículas } / \mathrm{m}^{2}\end{array}$ & $\begin{array}{c}\mathrm{N}^{\mathrm{o}} \text { de grãos/ } \\
\text { panícula }\end{array}$ & $\begin{array}{l}\text { Massa de } 1000 \\
\text { grãos }\end{array}$ & $\begin{array}{l}\text { Produtividade de } \\
\text { grãos }\end{array}$ \\
\hline Altura da planta & $0,77 * *$ & $-0,14 \mathrm{~ns}$ & $0,61 * *$ & $0,04 \mathrm{~ns}$ & $0,50 * *$ \\
\hline Comprimento da panícula & - & $-0,15 \mathrm{~ns}$ & $0,79 * *$ & $0,19 \mathrm{~ns}$ & $0,39 *$ \\
\hline $\mathrm{N}^{\mathrm{o}}$ de panículas por $\mathrm{m}^{2}$ & & - & $-0,27 \mathrm{~ns}$ & $0,05 \mathrm{~ns}$ & $0,12 \mathrm{~ns}$ \\
\hline $\mathrm{N}^{\mathrm{o}}$ de grãos por panícula & & & - & $-0,38 *$ & $0,46 * *$ \\
\hline Massa de 1000 grãos & & & & - & $-0,18 \mathrm{~ns}$ \\
\hline
\end{tabular}

*, ** e ns são, respectivamente, significativos a $5 \%$ e $1 \%$ e não-significativo pelo teste $\mathrm{t}$.

A aplicação de $\mathrm{N}$ aos 14 DAE proporcionou aumento no número de grãos por panícula, sendo essa relação melhor explicada por uma regressão linear (Figura 2). Vários autores relataram a influência do $\mathrm{N}$ no aumento do número de grãos por panículas de milheto (JORNADA et al., 2005; MESQUITA et al., 1998), e arroz (GUIMARÃES \& STONE, 2003). No entanto, a adubação nitrogenada aos 28 DAE não afetou o número de espiguetas por panícula, provavelmente pelo fato dessa aplicação ter sido realizada após a diferenciação das espiguetas, ou seja, na fase em que o número de espiguetas por panícula já estava determinado.

A massa de 1.000 grãos não foi influenciada pelas doses de nitrogênio e nem pela época de aplicação do fertilizante, apresentando valor médio de 3,9 g (Figura 2). Jornada et al. (2005) e Nakagawa et al. (2000) também não verificaram efeito do $\mathrm{N}$ na massa de grãos de milheto e aveia preta, respectivamente.

A produtividade de grãos foi incrementada pela aplicação de nitrogênio em cobertura, independentemente da época de aplicação (Figura 2). A aplicação aos 14 DAE proporcionou acréscimo linear na produtividade, enquanto que com a aplicação mais tardia (28DAE) os dados se ajustaram a uma regressão quadrática com a produtividade máxima estimada com a dose de $88,3 \mathrm{~kg} \mathrm{ha}^{-1}$ de $\mathrm{N}$. O aumento da produtividade proporcionado pelo $\mathrm{N}$, principalmente quando aplicado aos $14 \mathrm{DAE}$, foi reflexo dos aumentos no comprimento da panícula e no número de grãos por panícula, sendo verificadas correlações significativas entre essas variáveis (Tabela 1), indicando que esses componentes afetam diretamente a produtividade de grãos. Diversos autores relataram aumento na produtividade de grãos de arroz, aveia-preta, milheto e sorgo com a aplicação de $\mathrm{N}$ em cobertura (GUIMARÃES \& STONE, 2003; JORNADA et al., 2005; MAMAN et al., 1999; MESQUITA et al., 1998; NAKAGAWA et al., 1995; SUBBA REDDY et al., 1991). Vale destacar que foram obtidas boas produtividades em todos os tratamentos, pois segundo Zancanella et al. (2003), a cultivar AL Tibagi apresenta, na safra das águas, produtividade média entre 1.000 e $1.500 \mathrm{~kg} \mathrm{ha}^{-1}$.

Os resultados indicam que, mediante o uso de maiores doses de $\mathrm{N}$, será possível obter maior produtividade de palha e de grãos de painço, especialmente se a adubação for realizada no início do ciclo da cultura. No entanto, não se conhece o comportamento da cultura em solo de alta fertilidade e sob a aplicação de altas doses de $\mathrm{N}$, o que, possivelmente poderá causar acamamento das plantas. Assim, são necessários maiores estudos, especialmente no que se referem às práticas de manejo e adubação, no sistema de plantio direto, no qual essa cultura vem ganhando espaço na região centro-oeste, tanto para a produção de palha como para a produção de grãos.

\section{CONCLUSÕES}

A adubação nitrogenada em cobertura promoveu aumento na altura da planta, comprimento da panícula e, consequentemente, na produtividade de grãos da cultura do painço.

O número de grãos por panícula foi incrementado pela adubação nitrogenada apenas quando a aplicação foi realizada aos $14 \mathrm{DAE}$

A aplicação de $\mathrm{N}$ em cobertura, aos 14 dias após a emergência, proporciona acréscimos nas características agronômicas, até a dose de $120 \mathrm{~kg} \mathrm{ha}^{-1}$, acarretando aumento da produtividade de grãos do painço. 


\section{REFERÊNCIASBIBLIOGRÁFICAS}

BASAVARAJAPPA, R.; PRABHAKAR, A. S.; HALIKATTI. Effect of tillage practices, organics and nitrogen levels on growth components, dry-matter accumulation and physiological parameters in foxtail millet (Setaria italica). Indian Journal of Agronomy, New Delhi, v. 48, n. 2, p. 111-113, 2003.

CARAMBULA, M.; ELIZONDO, J. Producción de semillas in gramíneas forrajeras: I. importancia de la edad de las macollas e influencia del nitrógeno y de la defoliación. Boletim Estación Experimental Paysandú, Paysandú, n. 5, p. 111-137, 1968.

CLARK, R. B. Physiology of cereals for mineral nutrient uptake, use and efficiency. In: BALIGAR, V. C.; DUNCAN, R. R. (Eds.). Crops as enhancers of nutrient use. San Diego: Academic, 1990. p. 131-209.

EMPRESA BRASILEIRA DE PESQUISA AGROPECUÁRIA. Centro Nacional de Pesquisa de Solos. Sistema brasileiro de classificação dos solos. Rio de Janeiro, 1999. 412 p.

FURUHASHI, S. Efeito de doses e de época de aplicação de nitrogênio na cultura do painço em sucessão a mucunapreta. 1995. 31 f. Monografia (Graduação em Agronomia) Universidade Estadual Paulista, Jaboticabal, 1995.

GUIMARÃES, C. M.; STONE, L. F. Adubação nitrogenada do arroz de terras altas no sistema de plantio direto. Revista Brasileira de Engenharia Agrícola e Ambiental, Campina Grande, v. 7, n. 2, p. 210-214, 2003.

JORNADA, J. B. J.; MEDEIROS, R. B.; PEDROSO, C. E. S.; SAIBRO, J. C.; SILVA, M. A. Efeito da irrigação, épocas de corte da forragem e doses de nitrogênio sobre o rendimento de sementes de milheto. Revista Brasileira de Sementes, Pelotas, v. 27, n. 2, p. 50-58, 2005.

LIMA, E. V.Plantas de cobertura e calagem superficial na fase de implantação do sistema de plantio direto em região de inverno seco. 2004. 123 f. Tese (Doutorado em Agronomia/Agricultura) - Universidade Estadual Paulista, Botucatu, 2004.

LIMA, E. V.; CAVARIANI, C.; LIMA, P. L.; CRUSCIOL, C. A. C.; NAKAGAWA, J.; VILLAS-BOAS, R. L. Qualidade fisiológica de sementes de painço (Panicum dichotomiflorum Michx.) em função do tempo de mistura com o superfosfato triplo. Cultura Agronômica, Ilha Solteira, v. 9, n. 1, p. 177-189, 2000.

MALAVOLTA, E. ABC da adubação. São Paulo: Ceres, 1979. $292 \mathrm{p}$.

MALAVOLTA, E.; VITTI, G. C.; OLIVEIRA, S. A. Avaliação do estado nutricional das plantas: princípios e aplicações. 2. ed. Piracicaba: Potafos, 1997. 319 p.

MAMAN, N.; MASON, S. C.; GALUSHA, T.; CLEGG, M. D. Hybrid and nitrogen influence on pearl millet production in Nebraska: yield, growth, and nitrogen uptake, and nitrogen use efficiency. Agronomy Journal, Madison, v. 91, n. 5 , p. $737-743,1999$.

MESQUITA, E. E.; PINTO, J. C.; MORAIS, A. R. Doses de nitrogênio e métodos de semeadura no rendimento de sementes de milheto (Pennisetum americanum (L.) Leeke). Revista Brasileira de Zootecnia, Viçosa, v. 27, n. 2, p. 255261, 1998

NAKAGAWA, J.; CAVARIANI, C.; MACHADO, J. R. Adubação nitrogenada no perfilhamento da aveia-preta em duas condições de fertilidade do solo. Pesquisa Agropecuária Brasileira, Brasília, v. 35, n. 6, p. 1071-1080, 2000.

NAKAGAWA, J.; CAVARIANI, C.; MACHADO, J. R. Efeito da dose e da época de aplicação de $\mathrm{N}$ na produção e qualidade de sementes de aveia-preta. Científica, São Paulo, v. 23, n. 1, p. 31-43, 1995.

RAIJ, B. van; ANDRADE, J. C.; CANTARELLA, H.; QUAGGIO, J. A. Análise química para avaliação da fertilidade de solos tropicais. Campinas: Instituto Agronômico, 2001. 284 p.

SPEHAR, C. R.; LARA CABEZAS, W. A. R. Introdução e seleção de espécies para a diversificação do sistema produtivo nos cerrados. In: LARA CABEZAS, W. A. R.; FREITAS, P. L. (Eds.). Plantio direto na integração lavoura pecuária. Uberlândia: UFU, 2001. p. 179-188.

SORATTO, R. P.; LIMA, E. V.; SILVA, T. R. B.; BOARO, C. S. F.; CATANEO, A. C. Nitrogen fertilization of fall panicum cultivars (Panicum dichotomiflorum Michx.): biochemical and agronomical aspects. Scientia Agricola, Piracicaba, v. 61, n. 1, p. 82-87, 2004. 
SUBBA REDDY, G.; VENKATESWARLU, B.; VITTAL, K. P. R.; SANKAR, G. R. M. Effect of different organic material as source of nitrogen on growth and yield of sorghum (Sorghum bicolor). Indian Journal of Agricultural Sciences, New Delhi, v. 61, n. 8, p. 551-555, 1991.

ZANCANELLA, E. F.; BONATTI, J. L.; MARTUCCI, L. M
V. Cultura do painço: informações práticas. Campinas: CATI, 2003. 4 p. Folheto.

ZANCANELLA, E. F.; BONATTI, J. L.; MARTUCCI, L. M. V. Novos cultivares de painço. Disponível em: <http:// www.cati.sp.gov.br/novacati/tecnologias/painco/ novos_cultivares.htm>.Acesso em: 3 mar. 2006. 